Instrumental Achievements

\title{
Comparative X-Ray Studies of a Copper(I) Coordination Polymer with 1,2,4,5-Tetramethylmercaptobenzene (tmmb), $\left[(\mathrm{CuX})_{2}(\mathrm{tmmb})\right]_{n}(\mathrm{X}=\mathrm{Br}, \mathrm{I})$
}

\author{
Yusaku Suenaga*, Masahiko MaEkawa**, Takayoshi Kuroda-Sowa*, Megumu Munakata*† \\ Hiroshi Morimoto*, Nobuyuki Hiyama* and Susumu Kitagawa*** \\ *Department of Chemistry, Kinki University, Kowakae, Higashi-Osaka, Osaka 577, Japan \\ ** Research Institute for Science and Technology, Kinki University, Kowakae, Higashi-Osaka, Osaka 577, Japan \\ *** Metropolitan University, Minami-Osawa, Hachioji, Tokyo 192-03, Japan
}

Copper(I) shows its preferential behavior towards halide anions when forming infinite polymer backbone structures. A typical chain structure is shown in ref. 1. The coordination mode of the halide anions is important for the rational synthesis of metal complex polymers. Furthermore the use of sulfur-containing molecules as precursors for the synthesis of conductive or superconductive materials is of continuing interest. Wudl et al. reported on $\mathrm{Fe}$ (III), $\mathrm{Ni}(\mathrm{II}), \mathrm{Co}$ (II) and $\mathrm{Cu}$ (II) complexes with 1,2,4,5-tetrathiobenzene ${ }^{2}$, which show high conductivity and magnetic properties. However, their crystal structures have not been reported. In this study, we have characterized copper(I) complexes with 1,2,4,5-tetramethylmercaptobenzene (tmmb) crystallographically. In this paper we will discuss the structural differences of the halide anion $\mathrm{Cu}(\mathrm{I})$-tmmb complexes.

Yellow single crystals of $\left[(\mathrm{CuBr})_{2}(\mathrm{tmmb})\right]_{n}(\mathrm{tmmb}=$ 1,2,4,5-tetramethylmercaptobenzene) (1) were obtained from a mixture of $\mathrm{CuBr}(4.3 \mathrm{mg}, 30 \mathrm{mmol} / \mathrm{l})$ and tmmb $(5.2 \mathrm{mg}, 20 \mathrm{mmol} / \mathrm{l})$ in acetonitrile under purified argon after $5 \mathrm{~d}$. The tmmb was obtained from the reaction of 1,2,4,5-tetrafluorobenzene with dry 1,3-dimethyl-2imidazolidinone. ${ }^{3} \mathrm{X}$-Ray data collection was performed on a Rigaku AFC-7R diffractometer under the conditions given in Table 1. The structure was solved by the direct application of MITHRIL ${ }^{4}$ and empirical, spherical and absorption corrections were performed using a program called DIFABS 5 after an isotropic refinement of all the non-hydrogen atoms. The scattering factors and the anomalous dispersion corrections for non-hydrogen atoms were taken from the ref. 6 . Refinement of the nonhydrogen atomic positional and the thermal anisotropic parameters were performed by a full-matrix least-squares calculation. The positions of the hydrogen atoms were obtained by a difference Fourier synthesis. All of the calculations were performed using a TEXSAN crystallographic software package. ${ }^{7}$ The atomic positional parameters are given in Table 2 . Single crystals of $\left[(\mathrm{CuI})_{2}(\mathrm{tmmb})\right]_{n}(2)$ were also obtained from $\mathrm{CuI}$ insted of $\mathrm{CuBr}$ by a similar synthesis method. It should be
Table 1 Crystallographic data for $\left[(\mathrm{CuBr})_{2}(\mathrm{tmmb})\right]_{n}$

Formula: $\mathrm{CuBrS}_{2} \mathrm{C}_{5} \mathrm{H}_{7}$
Formula weight: 274.68
Crystal system: triclinic
Space group: $P_{1}$
$a=7.077(2) \AA$
$b=8.584(1) \AA$
$c=6.730(1) \AA$
$\alpha=96.26(1)^{\circ}$
$\beta=93.13(2)^{\circ}$
$\gamma=76.94(1)^{\circ}$
$V=395.7(1) \AA^{3}$
$D_{\mathrm{c}}=2.305 \mathrm{~g} / \mathrm{cm}^{3}$
$R=0.044, R w=0.056$
No. of reflections used=1676 $(I>3.00 \sigma(I))$
Measurement: Rigaku AFC-7R
Program system: TEXSAN
Structure determination: direct method (MITHRIL)
Refinement: full-matrix least square

Table 2 Final atomic coordinates and equivalent isotropic thermal parameters $B_{\mathrm{eq}}\left(\AA^{2}\right)$ of the non-hydrogen atoms for $\left[(\mathrm{CuBr})_{2}(\mathrm{tmmb})\right]_{n}$

\begin{tabular}{lllll}
\hline Atom & \multicolumn{1}{c}{$x$} & \multicolumn{1}{c}{$y$} & \multicolumn{1}{c}{$z$} & $B_{\text {eq }}$ \\
\hline $\operatorname{Br}(1)$ & $0.34170(6)$ & $0.47976(5)$ & $0.75737(6)$ & $2.06(1)$ \\
$\mathrm{Cu}(1)$ & $0.57146(8)$ & $0.31516(7)$ & $1.00158(8)$ & $2.34(1)$ \\
$S(1)$ & $0.3615(1)$ & $0.1675(1)$ & $1.1032(1)$ & $1.49(2)$ \\
$S(2)$ & $0.8012(1)$ & $0.1293(1)$ & $0.8079(1)$ & $1.66(2)$ \\
$C(1)$ & $0.6351(5)$ & $0.0575(4)$ & $0.6304(6)$ & $1.34(7)$ \\
$C(2)$ & $0.5746(5)$ & $0.1281(5)$ & $0.4557(6)$ & $1.50(7)$ \\
$C(3)$ & $0.4398(5)$ & $0.0718(4)$ & $1.3244(5)$ & $1.32(7)$ \\
$C(4)$ & $0.1526(8)$ & $0.3145(7)$ & $1.1978(9)$ & $3.3(1)$ \\
$C(5)$ & $0.9205(8)$ & $0.2380(8)$ & $0.6570(8)$ & $3.0(1)$ \\
\hline
\end{tabular}

$B_{\mathrm{eq}}=(4 / 3) \Sigma_{i} \Sigma_{j} \beta_{i j}\left(a_{i} \cdot a_{j}\right)$

To whom correspondence should be addressed. 


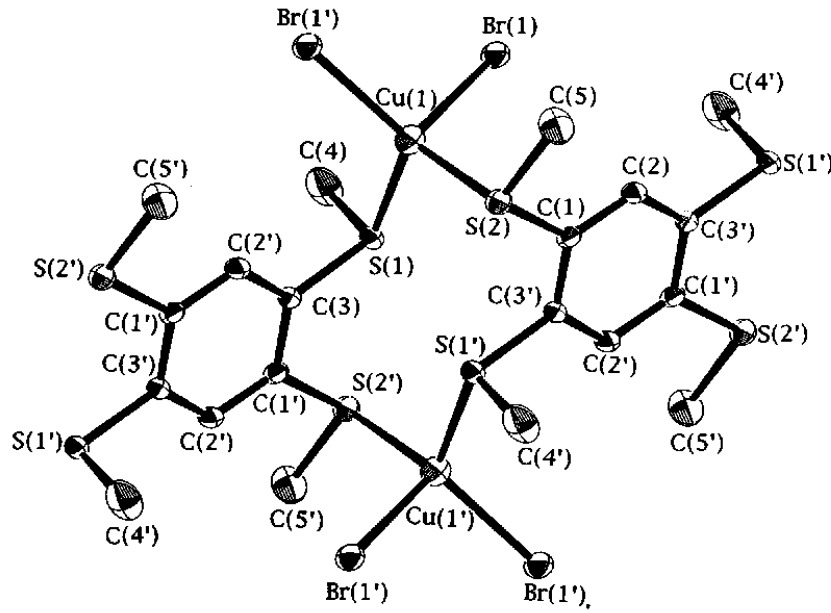

Fig. 1 ORTEP view of $\left[(\mathrm{CuBr})_{2}(\mathrm{tmmb})\right]_{n}(1)$ with the atom numbering scheme.

mentioned that rasults of a single-crystal X-ray analysis has already been preliminarily reported by Kitagawa et al. $^{8}$

An ORTEP view of (1) together with the atom numbering scheme is shown in Fig. 1, while Fig. 2 shows the molecular structure of (1). Selected bond distances and angles are listed in Table 3 . The $\mathrm{Cu}(\mathrm{I})$ atom is coordinated through an $\mathrm{S}$ atom to each of two tmmb molecules and to two bromides in a distorted tetrahedral geometry. Also, the two bromides are coordinated with one $\mathrm{Cu}(\mathrm{I})$ atom of a parallel chain, forming a twodimensional sheet structure.

The average $\mathrm{Cu}-\mathrm{S}$ distance of 2.337 (1) $\AA$ is within the normal range $(2.30-2.44 \AA)$ of $\mathrm{Cu}(\mathrm{I})$ complexes with thioether ligands. ${ }^{9-12}$ The $\mathrm{S}(1)-\mathrm{Cu}(1)-\mathrm{S}(2)$ angle of $105.31(4)^{\circ}$ indicates tetrahedral geometery. The tmmb
Table 3 Selected bond distances $(\AA)$ and bond angles $\left({ }^{\circ}\right)$ for $\left[(\mathrm{CuBr})_{2}(\mathrm{tmmb})\right]_{n}$

\begin{tabular}{lcll}
\hline $\mathrm{Br}(1)-\mathrm{Cu}(1)$ & $2.5527(7)$ & $\mathrm{Br}\left(1^{\prime}\right)-\mathrm{Cu}(1)$ & $2.4219(6)$ \\
$\mathrm{Cu}(1)-\mathrm{S}(1)$ & $2.330(1)$ & $\mathrm{Cu}(1)-\mathrm{S}(2)$ & $2.344(1)$ \\
$\mathrm{S}(1)-\mathrm{C}(3)$ & $1.781(4)$ & $\mathrm{S}(1)-\mathrm{C}(4)$ & $1.807(5)$ \\
$\mathrm{S}(2)-\mathrm{C}(1)$ & $1.789(4)$ & $\mathrm{S}(2)-\mathrm{C}(5)$ & $1.809(5)$ \\
$\mathrm{C}(1)-\mathrm{C}(2)$ & $1.384(5)$ & $\mathrm{C}\left(1^{\prime}\right)-\mathrm{C}\left(3^{\prime}\right)$ & $1.401(5)$ \\
$\mathrm{C}\left(2^{\prime}\right)-\mathrm{C}(3)$ & $1.395(5)$ & & \\
& & & \\
$\mathrm{Cu}(1)-\mathrm{Br}(1)-\mathrm{Cu}\left(1^{\prime}\right)$ & $77.26(2)$ & $\mathrm{Br}(1)-\mathrm{Cu}(1)-\mathrm{Br}\left(1^{\prime}\right)$ & $102.74(2)$ \\
$\mathrm{Br}(1)-\mathrm{Cu}(1)-\mathrm{S}(1)$ & $98.82(3)$ & $\mathrm{Br}(1)-\mathrm{Cu}(1)-\mathrm{S}(2)$ & $106.55(3)$ \\
$\mathrm{Br}\left(1^{\prime}\right)-\mathrm{Cu}(1)-\mathrm{S}(1)$ & $117.43(3)$ & $\mathrm{Br}\left(1^{\prime}\right)-\mathrm{Cu}(1)-\mathrm{S}(2)$ & $122.71(3)$ \\
$\mathrm{S}(1)-\mathrm{Cu}(1)-\mathrm{S}(2)$ & $105.31(4)$ & $\mathrm{Cu}(1)-\mathrm{S}(1)-\mathrm{C}(3)$ & $114.5(1)$ \\
$\mathrm{Cu}(1)-\mathrm{S}(1)-\mathrm{C}(4)$ & $105.6(2)$ & $\mathrm{C}(3)-\mathrm{S}(1)-\mathrm{C}(4)$ & $99.3(2)$ \\
$\mathrm{Cu}(1)-\mathrm{S}(2)-\mathrm{C}(1)$ & $97.6(1)$ & $\mathrm{Cu}(1)-\mathrm{S}(2)-\mathrm{C}(5)$ & $108.6(2)$ \\
$\mathrm{C}(1)-\mathrm{S}(2)-\mathrm{C}(5)$ & $102.1(2)$ & $\mathrm{S}(2)-\mathrm{C}(1)-\mathrm{C}(2)$ & $122.5(3)$ \\
$\mathrm{S}(2)-\mathrm{C}(1)-\mathrm{C}\left(3^{\prime}\right)$ & $117.9(3)$ & $\mathrm{C}(2)-\mathrm{C}(1)-\mathrm{C}\left(3^{\prime}\right)$ & $119.6(3)$ \\
$\mathrm{C}(1)-\mathrm{C}(2)-\mathrm{C}\left(3^{\prime}\right)$ & $120.6(3)$ & $\mathrm{S}(1)-\mathrm{C}(3)-\mathrm{C}\left(1^{\prime}\right)$ & $120.7(3)$ \\
$\mathrm{S}(1)-\mathrm{C}(3)-\mathrm{C}\left(2^{\prime}\right)$ & $119.6(3)$ & $\mathrm{C}\left(1^{\prime}\right)-\mathrm{C}(3)-\mathrm{C}\left(2^{\prime}\right)$ & $119.8(3)$
\end{tabular}

Symmetry code: $-x,-y,-z$.

inter-chain distance is far enough apart, that no specific intermolecular stacking was found. The close S...S distance between the chains of $4.4 \AA$, is not necessarily indicative of the $\mathrm{S} \cdots \mathrm{S}$ interaction found in $\mathrm{Cu}(\mathrm{I})$ complexes with tetramethylmercaptotetrathiafluvarate. ${ }^{13}$

The IR spectrum of the free tmmb molecule shows a S$\mathrm{CH}_{3}$ stretching band at $846 \mathrm{~cm}^{-1}$. Upon coordination with copper(I) this frequency shifts to $883 \mathrm{~cm}^{-1}$. The above data clearly shows formation of a complex.

The molecular structure of complex (2) is shown in Fig. 3. Two $\mathrm{Cu}$ atoms are coordinated to one tmmb ligand in complex (2), while four $\mathrm{Cu}$ atoms are coordinated to one tmmb ligand in complex (1).

Complex (2) forms a one-dimensional zig-zag structure. A comparison of bonding properties between

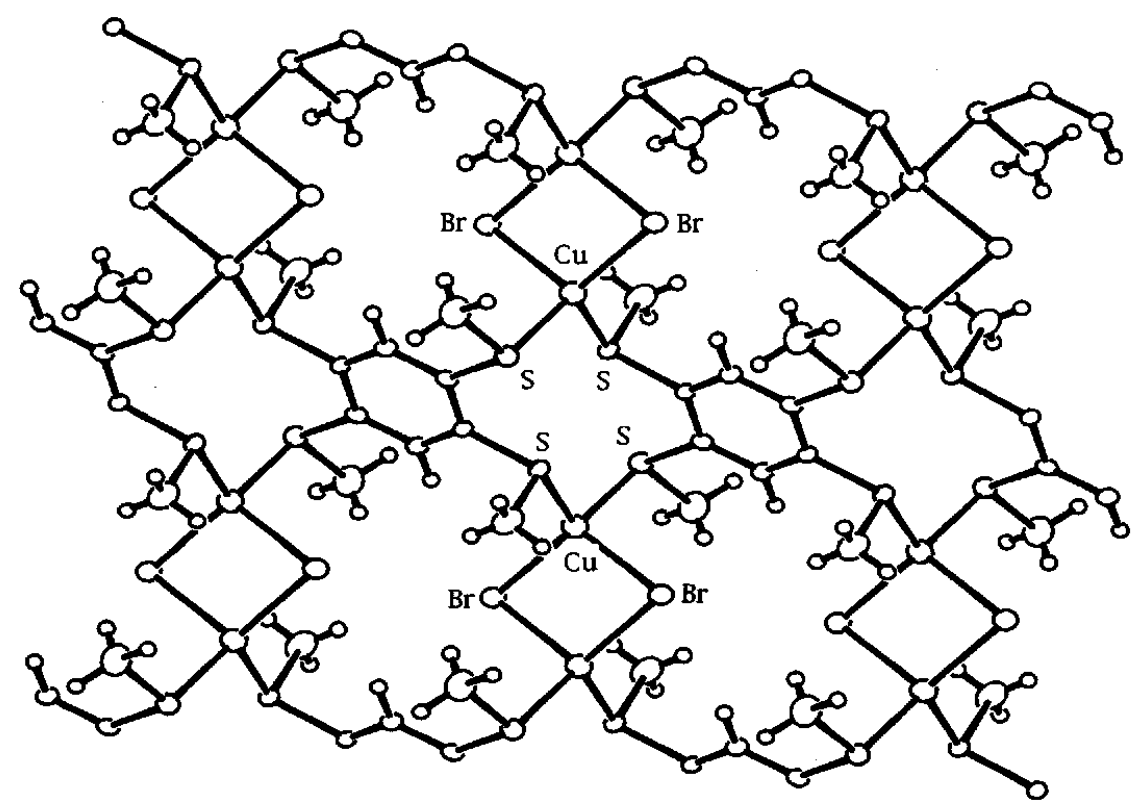

Fig. 2 Molecular structure of $\left[(\mathrm{CuBr})_{2}(\mathrm{tmmb})\right]_{n}(1)$. 


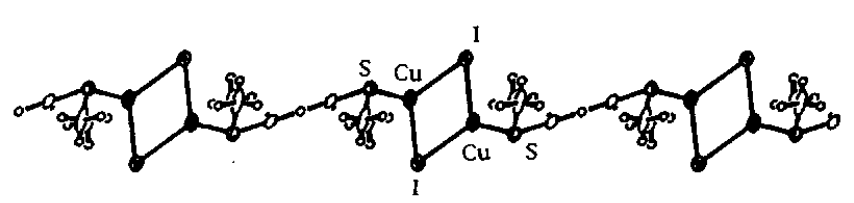

Fig. 3 Molecular structure of $\left[(\mathrm{CuI})_{2}(\mathrm{tmmb})\right]_{n}(2)$.

Table 4 Comparative bonding properties between $\left[(\mathrm{CuBr})_{2}(\mathrm{tmmb})\right]_{n}$ and $\left[(\mathrm{CuI})_{2}(\mathrm{tmmb})\right]_{n}$

\begin{tabular}{l|c|c}
\hline & {$\left[(\mathrm{CuBr})_{2}(\mathrm{tmmb})\right]_{n}$} & {$\left[(\mathrm{CuI})_{2}(\text { tmmb })\right]_{n}$} \\
\hline $\mathrm{Cu}-\mathrm{S}$ & $2.337 \AA$ & $2.363 \AA$ \\
$\mathrm{Cu}-\mathrm{X}$ & $2.487 \AA$ & $2.596 \AA$ \\
& & \\
$\mathrm{S}-\mathrm{Cu}-\mathrm{S}$ & $105.31^{\circ}$ & $85.57^{\circ}$ \\
$\mathrm{X}-\mathrm{Cu}-\mathrm{X}$ & $102.74^{\circ}$ & $114.30^{\circ}$ \\
$\mathrm{Cu}-\mathrm{X}-\mathrm{Cu}$ & $77.26^{\circ}$ & $65.69^{\circ}$ \\
\hline
\end{tabular}

complexes (1) and (2) is given in Table 4. The arrangement of $\mathrm{Cu}(\mathrm{I})$ in complex (2) is a distorted tetrahedral geometry, which is in contrast to that in complex (1). The structure difference of these complexes is thought to be due to the halide atom size. The van der Waals radius of the halide atom is $1.95 \AA(\mathrm{Br})$ and $2.10 \AA$ (I), respectively. Considering the van der Waals packing ratio, it is difficult for complex (2) to form a twodimensional sheet structure. A similar structural difference in halide anions has been reported for the $\mathrm{Cu}(\mathrm{I})$ complexes with tetraethylmercaptotetrathiafluvarate. ${ }^{14}$

The electrical resistivity of the compacted pellets was measured by the conventional two-probe technique. Both complexes (1) and (2) were insulators at room temperature $\left(\sigma_{25^{\circ} \mathrm{C}}<10^{-12} \mathrm{~S} \mathrm{~cm}^{-1}\right)$. Their iodine-doped black products in powder form also behave as insulators.
We thank Ms. Mikiko NaKamura and Mr. Toshiyuki KoJima for their assistance with the X-ray measurements.

\section{References}

1. S. Kitagawa and M. Munakata, Tr. Inorg. Chem., 3, 437 (1993).

2. C. W. Dirk, M. Bousseau, P. H. Barrett, F. Moraes, F. Wudl and A. J. Heeger, Macromolecules, 19, 266 (1986).

3. C. W. Dirk, S. D. Cox, D. E. Wellman and F. Wudl, J. Org. Chem., 50(13), 2395 (1980).

4. "MITHRIL", J. Gilmore, J. Appl. Crystallogr., 17, 42, Univ. of Glasgow, Scotland, 1984.

5. "DIFABS", N. Walker, D. Stewart, Acta Crystallogr., Sect $A, 39,158$ (1983).

6. "International Tables for X-ray Crystallography", Vol. IV, The Kynoch Press, Birmingham, 1974.

7. "TEXSAN", TEXRAY Structure Analysis Package, Molecular Structure Corporation, The Woodlands, Tx, USA, 1985.

8. S. Kitagawa et al., Abstracts of Papers, The 46th Symposium on Coordination Chemistry of Japan, Higashi-Osaka, September, 1996, p. 390.

9. M. Munakata, T. Kuroda-Sowa, M. Maekawa, A. Hirota and S. Kitagawa, Inorg. Chem., 34, 2705 (1995).

10. M. B. Inoue, M. Inoue, M. A. Bruck and Q. Fernando, $J$. Chem. Soc., Chem. Commun., 1992, 515.

11. E. W. Ainscough, A. M. Brodie and J. M. Husbands, J. Chem. Soc., Chem. Commun., 1985, 151.

12. E. W. Ainscough, A. M. Brodie and K. C. Palmar, J. Chem. Soc., Chem. Commun., 1976, 2375.

13. M. Munakata, L. P. Wu, X. Gan, T. Kuroda-Sowa and Y. Suenaga, Mol. Cryst. Liq. Cryst., 284, 319 (1996).

14. X. Gan, M. Munakata, T. Kuroda-Sowa, M. Maekawa and Y. Misaki, Polyhedron, 14, 1343 (1995).

(Received June 2, 1997)

(Accepted September 3, 1997) 